\title{
Health Care System Financing and Accessibility in the United States vs. Australia
}

Haitham Mohammed*

Department of Pharmacy, MPH, Griffith University, Australia

\begin{abstract}
A comparison between health care system financing and accessibility in Australia and the United States, followed by focus on some disadvantaged groups in the United States, namely the AMESH, black Americans, Hispanics, and native Americans, and how two major problems of the American health care system, which are accessibility, and affordability affecting the health status of these marginalized groups.
\end{abstract}

Keywords: Health; Funding; Government

\section{FUNDING THE AUSTRALIAN HEALTH CARE SYSTEM}

The Australian health care system is financed by different levels of government, ranging from national state/territory to local and to a less extent by private insurers. The government is the major contributor of health funding it is estimated that Almost $70 \%$ of total health expenditure during 2011-2012 was funded by governments, with the Australian Government contributing $42.4 \%$ and state and territory governments $27.3 \%$. The remaining $30.3 \%$ ( $\$ 42.4$ billion) was paid for by patients (17\%), private health insurers $(8 \%)$ and accident compensation schemes $(5 \%)$ (AIHW 2013b).

The Australian government has obligations to fund health care via some mechanisms:

Medicare benefits scheme (MBS) which are services offered by Medicare and subsidized by the Australian government which encompasses procedures, consultations, and tests. Patients will get compensated $100 \%$ for any GP related services, $85 \%$ of any non-GP related services in public hospitals, however will get $75 \%$ compensation in a private setting. Patient will sometimes to pay to cover the fee gap [1].

Medicare is funded by taxation revenue, and $1.5 \%$ by Medicare levy out of the pocket cost is usually offset by Medicare safety net.

The pharmaceutical benefits scheme (PBS) a list that has all the medications available to be dispensed by a pharmacist to a patient at a government-subsidized price. The PBS started since 1984, by offering free medications for pensioners and 139 disease preventing and lifesaving drugs free for other people.

National partnership agreements (NPAS) fund the delivery of specific projects in states and territories "These currently include hospital reform, preventive health, workforce reform, Aboriginal and Torres Strait Islander health, elective surgery, e-health, vaccines, health infrastructure projects and a range of health services, including cancer screening and health protection programs" [2].

The private health insurance rebate, which helps Australians to get health care in private hospitals, and other ancillary services such as dental care, according to the private health insurance administration council (PHIAC) $45 \%$ of the Australians has private health insurance and almost $55 \%$ for ancillary services such as dentistry and optometry. The common wealth government provides a rebate for insurance premiums and charging high earner for extra Medicare levy surcharge if they choose not to enroll into private hospital insurance.

Health services for veterans which is provided through various providers: medical officer scheme, the repatriation pharmaceutical benefit scheme (RPBS), and for the treatment in private hospitals the repatriation private patients scheme.

\section{HEALTH SERVICES DELIVERY IN AUSTRALIA}

Health services are provided by a various number of providers including the government at different levels, federal, state, and local in addition to private and non for profits organizations.

Correspondence to: Haitham Mohammed, Department of Pharmacy, MPH, Griffith University, Australia, Tel: +61406121754, E-mail: Haitham04@hotmail.com

Received: March 19, 2019; Accepted: April 15, 2019; Published: April 22, 2019

Citation: Mohammed H (2019) Health Care System Financing and Accessibility in the United States vs. Australia. Health Care Current Reviews. doi: $10.35248 / 2375-4273.19 .7 .241$.

Copyright: (C) 2019 Mohammed H. This is an open-access article distributed under the terms of the Creative Commons Attribution License, which permits unrestricted use, distribution, and reproduction in any medium, provided the original author and source are credited. 


\section{The providers}

1. Health promotion and disease prevention

2. Communicable disease prevention

3. The communicable disease network Australia (CDNA)

Established in 1989 with its primary aim to control and prevent communicable diseases, to respond in a timely manner to any possible outbreaks, providing high quality surveillance. CDNA works under the umbrella of the Australian Health Protection Principal Committee (AHPPC), they meet every 14 days to assess and take actions in respond to information available in regards of communicable diseases including: HIV, Sexually transmitted diseases, and Vaccines preventable diseases [3].

\section{Primary care}

Primary care GPs services: there are 7151 private practices which is funded via Medicare dentists mostly private services, nevertheless with state funding for primary dental care programme and partial dental care for the elderly, the disabled, single parents with health care cards and the unemployed.

\section{Secondary and tertiary services}

Inpatient and outpatient services:

1. 752 public hospitals in 2010-2011 (AIHW Australian public hospitals statistics 2010-11) provide acute care, palliative care, newborn care, providing services for a larger proportions of indigenous Australians, and low socioeconomic people compared to private hospitals services are funded by Medicare.

2. 17 public psychiatric hospitals in 2010-2011.

3. 581 private hospitals in 2009-2010, and Medicare funds a proportion of the services provided that it is listed in the Medicare benefit scheme (MBS).

\section{Ambulance service}

The six states and two territories provide funding and delivery for this service, which includes providing pre-hospital acute cate, transportation, and organizing the subsequent necessary medical support, however in western Australia, South Australia, and the Northern territory the pre-hospital service is provided by a private company, the ambulance service is only limited to transportation [4].

\section{Long term and continuing care services}

It comprises aged care services (primarily funded by the Australian government), disability care services and palliative care [5].

\section{THE UNITED STATES OF AMERICA}

\section{Health care funding}

Public resources fund $48 \%$ of the health care services, $40 \%$ is covered by private third party organization, while individuals contribute to the remaining $12 \%$. Although the figures show almost equal proportion between public and private financing. Only 30\% of the American population is covered by public financing through Medicare and Medicaid. While the majority of Americans receive health care service privately (54\%). One in every six Americans is uninsured, even among the insured Americans high out of the the pockets costs will hinder receiving appropriate treatment. Medical costs are responsible for over $60 \%$ in the bankruptcy of people in the United States [6].

\section{A) Financing the American health care system}

\section{Public}

Medicare: Is a federal program for all US citizens 65 years old or elder. Age restrictions are not applied in some cases of disabilities and it is not depending on income. It is divided into four parts:

Part A: Hospital coverage: funded by taxation, and deductions from social security.

Part B: Medical insurance, funded by taxation, and deductions from social security as well.

Part C: Private part of Medicare can be purchased privately and also covers all services provided under past $\mathrm{A}$ and part $\mathrm{B}$ and it is paid by out of the pocket money from the individuals.

Part D: Drug prescriptions coverage, funded by out of the pocket money from individuals, which was added recently to address the problem of increased drug costs.

Medicaid: Is a joint federal and state program, the federal government pays up to $50 \%$ for each state Medicaid program. unlike the Medicare program which is available to everyone, Medicaid is targeting people with low-income, in some states being poor is not enough to be eligible for Medicaid, but it is mandatory not to have more than few thousands American dollars in liquid assets [7].

\section{Private insurance}

Provided by either for-profit or non-for profit companied which are accredited in each state most private insurance is provided by the employers to the employees and the premium is to be shared between the employers and the employees, individuals themselves can purchase insurance but at higher costs, also they undergo screening before being accepted as they can be denied based on their current medical conditions as they are likely to attract more health care services [8].

\section{B) Health care delivery in the United States}

There is no universal health care delivery that is shared equally by the entire citizen, instead multiple subsystems have emerged either under the influence of the market force or as an emerging need to look after certain segment of the American society.

US primary care: Delivery of primary care is subdivided into family medicine, general internal medicine and general pediatrics. With a combined workforce of 220.000 doctors and more than 100000 nurses and physician assistants working in the primary care [9].

US secondary care: That includes specialty care

i) Imaging and testing

ii) Pharmaceutical care

iii) Acute care: Divided into inpatient care and outpatient care

iv) Rehabilitation and intermediate care

v) Long term care: Home care, assisted living, and nursing home care

vi) Palliative care: As the United States does not have a universal health care system so getting access will depend whether the patient is insured or uninsured. The patients will need to get in contact with a primary care providers, after evaluation the patient may get referral to the specialist, or in case if the patient is in preferred 
provider organization or a subscriber of fee for service insurance, he or she can go directly to the specialist, based on the patients' medical condition, the specialist may ask for imaging or treatment. Private health insurance usually does not cover long term care, while public insurance (such as Medicare and Medicaid) there is always limitations on the length of coverage and the extent as well [7].

\section{COMPARATIVE ANALYSIS OF THE AUSTRALIAN HEALTH CARE SYSTEM VS. THE AMERICAN HEALTH CARE SYSTEM}

\section{A) Healthcare expenditure}

Australia spent 9.1\% GDP in 2011-2011 which is slightly lower than the average of OECD countries which stand at 9.4\%, and the United States ranked number one with $16.9 \%$. If we break down the percentage of GDP expenditure over public and private health care, Australia spent $6.2 \%, 2.9 \%$ respectively of the GDP in 2011 2012. While the United States spent $8 \%$ and $8.9 \%$ on public and private health care respectively in the same year [10].

\section{B) GPs remuneration}

The remuneration for general practitioners in Australia compared to the average wage in Australia was 1.7 in 2011, while in the United States it is 3.5 times higher than the average earners. In 2006 the average GP in Australia earned 91.000 American dollars, while in the United States Gps earned 161,000 American dollars $[11,12]$.

\section{C) Accessibility}

A survey conducted in 2013 showed that 37\% of American patients did not receive the recommended treatment, did not get their prescription dispensed or did not see a doctor when sick compared to $11 \%$ in Australia [13]. Australia provides a health care system that is well accessible for all citizen, permanent residents, and countries that Australia has a reciprocal healthcare agreement with like Sweden, Malta and New Zealand.

The United States does not have universal healthcare system, the system is considered unreliable to provide timely manner health care service. In 2006, 25\% of Americans reported that access to health care is the second most important problem facing Americans.

\section{ACCESS INEQUALITY TO HEALTH CARE IN THE UNITED STATES}

In 2010 a survey found out that only $70 \%$ of the Americans were confident that they would get the proper treatment if they had any health issues [13]. Racial and ethnic inequality remains a barrier for the Americans in the American health care system [14].

\section{African Americans}

Although African Americans constitute a small proportion of the American society, they are highly disadvantaged when it comes to health, in 2010; African Americans constitute 12.2\% of the American population (overview of race and Hispanic origin 2010). In 1990 was reported that a black American living in Harlem will die earlier than an average resident of Bangladesh [15].

The following statistics will show the health disparity of the African Americans:

\section{A) Infant mortality}

According to the office of minority health infant mortality occur at a rate of $14.1 \%$ which as double as the rate of white Americans.

\section{B) Cardiovascular diseases}

According to the national centre of minority health and health disparity reports, African Americans have 20\% higher chance of cardiovascular mortality, and higher chance of getting high blood pressure disease than any other racial groups.

\section{C) Cancer}

African Americans have the highest rate of cancer-related mortality; according to the national centre of minority health black women have the highest rate of breast cancer and cervical cancer in the United States.

\section{E-HIV DISEASE}

According to the centers for disease control, black women are 18 times more likely to be diagnosed with AIDS than white Americans [16].

\section{FACTORS FOR THE AFRICAN AMERICANS HEALTH DISPARITY}

It is a complex problem and can be contributed to different factors, the socioeconomic status of the African Americans is at the lowest rank in the American society, proved by African American children are 3 times more likely to live in poverty compared to Caucasians and when it comes to employment, the unemployment rate of the African American is as twice as the Caucasians, a full time working African Americans earn $72 \%$ of comparable white male and $85 \%$ of a comparable white woman.

The second factor that has played a role in the poor health status of African Americans is genetics, Black Americans have highest rate of all leading causes of death except COPD and liver diseases. Highest rates of all cancer types except myeloma, the highest incidence of prostate cancer, as black Americans have as much as twice as white Americans prostate cancer which could be due to genetic factors [17].

The last factor that contributed to the deteriorated health of black Americans is life styles, for example black women tend to exercise less compared to white women (centre for disease control and prevention, 2007a), that can traced to the preferred body image for black women which is satisfaction with bigger body size compared to Caucasian women.

\section{American Indians and Alaska native}

$0.8 \%$ of the American population is American Indians or Alaska native according to an estimation from the American bureau of statistics in 2008. Americans Indians or Alaska native has fairly poor health compared to other minority groups in the United States, manifested in the following information:

Diabetes: The most challenging health problem facing native Americans, as it is reported that native Americans have the highest type 2 diabetes prevalence in the world, though diabetes type 2 commonly affecting adults it has become a threatening problem for native American children who have the highest rate compared to all other minority groups [18].

Tuberculosis: In 1998 the American lung association reported that the incidence rate of tuberculosis among Native American was 
12.6 cases per 100000 which are five times more than rate for white Americans which were 2.3.

Influenza and pneumonia: For the period between 1994-1996, the Indian Health Services estimated that death rate from influenza or pneumonia was $71 \%$ greater than the national American rate.

\section{FACTORS LEADING TO THE NATIVE AMERICAN HEALTH DISPARITY}

\section{Racial discrimination}

National Institutes of health acknowledge that racial bias is major factor for health disparity in the United States [19].

\section{Accessibility}

For more than half millions Native Americans who live in reservations where the climate is the worst in the united states, Anslem Roanhorse, director of the Division of Health for the Navajo Nation, quoted that on the Navajo reservation "78 percent of the public roads are unpaved and 60 percent of the homes lack telephone service". So the location and inadequate transportation have affected negatively the health of Native Americans [20].

\section{Hispanics}

Hispanics are the largest minority group in the United States; they make up $15 \%$ of the American population. The US centre for disease control and prevention quoted that "Hispanics are two time more likely than non-Hispanics blacks and 3 times more likely than non-Hispanics whites not to service by a regular health providers".

\section{AMESH \\ Is a group of traditionalist Christian group that characterized by living simile and being anti-technology, due to their religious beliefs they are not covered by any health insurance, and refuse to take immunization. As a result of endogamy, they are victims to some genetic diseases [21]. \\ PROBLEMS FACING THE AMERICAN HEALTH CARE SYSTEM}

\section{Accessibility}

Not all the Americans have equal access to the health care system; America is the only industrial nation that does not have a universal health system. The uninsured Americans numbered 38-42 million according to estimation from the census bureau of statistics. This group of people does not have health insurance for various reasons, such as their employer does not provide health insurance, or the premium to be shared with the employer is unaffordable for them or they are not qualified to have health insurance (not working on full time bases or newly hired).

Having insurance is tightly related to have a better health, as uninsured people are less likely to have a regular source of health care, timely screening and preventive services. Uninsured people are less likely to have regular check-ups which can delay diagnosis of some diseases the early diagnosed the better the outcome such as breast cancer, colorectal cancer, so uninsured people would in poorer health compared to insured people in the US [22].

\section{Cost/Affordability}

The American public expressed their concerns about the increased prices of health services and medications. In a survey about how much an average American will spend in 2006 67\% reported that they spent too much. While only $17 \%$ reported too little [23].

Americans believe the profits made by pharmaceutical companies and insurance companies are the reason for high cost of health services, as shown in that survey of 2005 .

$35 \%$ of Americans thought profits were the reasons for the scratching prices, while only $5 \%$ blamed doctors for over-charging patients [23-25]. The Americans are worried about their ability to afford health care services; in 2006, 32\% of the Americans were worried about the lack of ability to finance their needed health care services.

In 2010 Obama care was signed into law, to curb those two major problems affecting the American health care system, primary goals were providing more Americans with access to affordable health care services [17].

\section{CONCLUSION}

Health is considered as a good that you need to buy in the United States, while in Australia it is a human right and a privilege for every citizen. Although the United stated spends more than Australia on health care, they are still faced by accessibility and affordability problems that have disadvantaged some groups in the American society, such as AMESH, black Americans, Hispanics, and native Americans, so a conclusion can be drawn that the health care system in Australia fares a way better than the United States.

\section{REFERENCES}

1. https://chf.org.au/publications/what-mbs

2. The Australian Bureau of statistics. Health care delivery and financing 2012.

3. http://www.health.gov.au/internet/main/publishing.nsf/ content/cda-cdna-cdna.htm

4. Eburn M, Bendall J. Provision of Ambulance Services in Australia: A legal argument for the national registration of paramedics. Austr J Paramed. 2010;8(4):8.

5. WHO. Health care delivery profile: Australia 2012.

6. Andrew JB, LYU, Pauline R, Thomas R. Health system in transition. USA Health System Rev. 2013;15(3):31.

7. James M. Medicare vs. Medicaid: What's the Difference? 2019.

8. Roger IS. Overview of health care financing 2016.

9. Phillips RL. Primary care in the United States: Problems and possibilities. BMJ Brit Med J. 2005;331:1400-1402.

10. OECD. OECD health statistics: How does Australia compare 2014.

11. OECD. Remuneration of doctors (general practitioners and specialists) in Health at a Glance 2013: OECD Indicators 2013.

12. Congressional resource services. Analysis of remuneration of health professionals 2006.

13. Schoen S, Robin O, Squires D, Doty MM. Access, Affordability and Insurance Complexity are often worse in the United States Compared to 10 Other Countries 2013.

14. American College of Physicians. Disparities remain a challenge in U.S. health care system 2010. 
15. McCord C, Freeman HP. Excess mortality in Harlem. N Engl J Med. 1990;322:173-177.

16. http://www.netwellness.org/healthtopics/aahealth/ disparities.cfm

17. https://obamacarefacts.com/obamacare-facts/

18. Acton KJN, Rios B, Moore K, Querec L, Geiss LS, Michael ME. Trends in Diabetes Prevalence among American Indian and Alaska Native Children, Adolescents and Young Adults. Am J Public Health. 2002;92(4):1485-1490.

19. https://obssr.od.nih.gov/

20. US Commission on Civil Rights. Native American Health Care Disparities 2004.
21. Orton NC, Innes AM, Chudley AE, Bech-Hansen NT. Unique disease heritage of the Dutch-German Mennonite population. Am J Med Genet A. 2008;146(8):1072-1087.

22. Coleman MS. Care without Coverage: Too Little, Too Late. Inst Med. 2002.

23. Pew Research Center 2006.

24. Blendon RJ, Brodie M, Benson JM, Altman DE, Buhr T. Americans Views of Health Care Costs, Access and Quality. The Milbank Quarterly. 2006;84(4):623-657.

25. Richard SC. Genetic Factors in Ethnic Disparities in Health. National Academies Press 2004. 